\title{
Interface Behavior and Interaction Mechanism between Vanadium-Titanium Magnetite Carbon Composite Briquette and Sinter in Softening-Melting-Dripping Process
}

\author{
Wei ZHAO, ${ }^{1)}$ Mansheng $\mathrm{CHU},{ }^{2) *}$ Hongwei GUO, ${ }^{1)}$ Zhenggen $\mathrm{LIU}^{2)}$ Bingji YAN ${ }^{1)}$ and Peng $\mathrm{LI}^{11}$ \\ 1) School of Iron and Steel, Soochow University, Suzhou, 215137 China. \\ 2) State Key Laboratory of Rolling and Automation, Northeastern University, Shenyang, 110819 China.
}

(Received on June 2, 2020; accepted on August 12, 2020; J-STAGE Advance published date: November $22,2020)$

\begin{abstract}
As an innovative and promising BF iron-bearing burden, the vanadium-titanium magnetite carbon composite briquette (VTM-CCB) charging significantly affects the softening-melting-dripping characteristics and cohesive zone of the mixed burden. In this study, the interface behaviors between VTM-CCB and sinter were investigated by conducting interrupted softening-melting experiments to elucidate intrinsic structure evolution and interaction mechanisms. During softening, when the FC/O ratio of VTM-CCB ranges from 0.8 to 1.0, the molten slag-metal coexisting structure formed at the interface, thereby promoting the shrinking and decreasing $T_{4}$ and $T_{40}$. However, with increasing $F C / O$ ratio higher than 1.0 , the interface slagging and bonding would be suppressed due to the unconsumed carbon particles. During melting, the increasing of $\mathrm{FC} / \mathrm{O}$ ratio would lower the $\mathrm{FeO}$ content and decrease the molten slag, and the interface layer transformed from molten slag-iron coexisting structure to dense metallic iron shell, suppressing the collapse of molten mixtures and increasing $T_{\mathrm{s}}$. In the dripping process, increasing the $\mathrm{FC} / \mathrm{O}$ ratio appropriately could promote the interface iron carburization and the aggregation of molten iron, thereby decreasing $T_{\mathrm{D}}$ and improving the dripping performance. Besides, the VTM-CCB, acting as skeleton in the molten mixtures, could provide more gas channels to improve the permeability of packed bed. However, as the FC/O ratio exceeds 1.2 , the $\mathrm{Ti}(\mathrm{C}, \mathrm{N})$ would precipitate at the slag-metal interface and deteriorate the fluidity of molten mixtures, thereby deteriorating the gas permeability and increasing $T_{D}$ notably. Fully considering the softening-melting-dripping characteristics and the gas permeability, the appropriate FC/O ratio of VTM-CCB should not be higher than 1.2.
\end{abstract}

KEY WORDS: vanadium-titanium magnetite carbon composite briquette; sinter; interface behavior; softening-melting-dripping characteristics; gas permeability.

\section{Introduction}

Vanadium-titanium magnetite (VTM), a type of complex iron ore containing iron, vanadium, titanium, is widely distributed in China, America, Russia, and South Africa. ${ }^{1-3)}$ Currently, vanadium-titanium magnetite sinter and pellet are conventionally used as the main feedstock of blast furnace (BF) smelting. However, due to the insufficient reducibility of VTM-sinter and VTM-pellet, the FeO content increased and the softening-melting temperature decreased obviously. Besides, the high viscosity of Ti-bearing slag system tends to increase the dripping temperature of molten slag and iron. As a result, the thickness of cohesive zone increased and the gas permeability deteriorated. ${ }^{4,5)}$

\footnotetext{
* Corresponding author: E-mail: chums@smm.neu.edu.cn
}

Large amounts literatures demonstrated that the gas permeability of blast furnaces mainly correlated to the cohesive zone phenomenon. Relevant researches dedicated to address and optimize the cohesive zone performance mainly concerned on the slag viscosity adjustment, nut coke-ore mixing, iron-bearing materials (sinter and pellet) metallurgical properties improvement, innovative feedstock of blast furnace charging, etc. ${ }^{6-14)}$ Carbon composite iron ore hot briquette $(\mathrm{CCB})$, exhibiting great reducibility due to the closely adjoining carbon and iron ore accelerating the carbon gasification and iron oxides reduction, was put forward as innovative BF burden aiming to realize low-carbon and low-temperature ironmaking. ${ }^{15-19)}$ Simultaneously, the CCB was widely applied to process low-grade and composite iron ore due to its outstanding reducibility. ${ }^{20-23)}$ Vanadiumtitanium magnetite carbon composite briquette (VTM-CCB) 
was prepared by briquetting the VTM concentrates and coal fine mixtures followed heat treatment. Our previous researches ${ }^{24,25)}$ indicate that the VTM-CCB exhibits excellent metallurgical properties such as compressive strength, reduction degradation property and reduction swelling property, and meets the requirements of BF smelting. Therefore, the charging of high-reducibility VTM-CCB is promising to promote the reduction and improve the softening-melting behavior and gas permeability of mixed burden.

In BF smelting process, the interface behavior and interaction between different iron-bearing materials during softening and melting has a significant effect on the primaryslag formation behavior, thereby influencing the cohesive zone and gas permeability phenomenon. Wu et al. ${ }^{27,28)}$ found that the interaction between sinter of high basicity and lump ore would improve the formation temperature, viscosity, and fluidity of primary-slag. She et l $^{29)}$ demonstrated that the softening-melting properties of the lump ore or oxidized pellet could be dramatically improved by the interaction between lump ores (or oxidized pellets) and metalized pellets, while there was no obvious interaction between sinter and metalized pellets. Kaushik and Fruehan ${ }^{30)}$ found the interaction between acid and olivine fluxed pellet mainly occurred in four stages, namely sintering of solid phases at interface, incipient melt formation, interaction of liquid at interface and interaction of the cores of the material. All these reported literatures about the interface behavior and interaction between iron-bearing materials were mainly concerned about sinter, acid pellet, lump ore, fluxed pellet, and metalized pellet.

Currently, the main iron-bearing materials for BF smelting VTM include high basicity VTM sinter and acid oxidized VTM pellet. As a new type of carbon-bearing materials, the basicity of VTM-CCB is close to the acid oxidized VTM pellet due to the preparation without flux addition. Therefore, it seems more feasible to replace the VTM pellet with VTM-CCB in the mixed burden. To better understand the effect of VTM-CCB on the softening-melting characteristics and gas permeability of the sinter/VTM-CCB mixtures, the interface behavior and interaction between sinter and VTM-CCB during softening-melting process were investigated in this study. Firstly, the effect of $\mathrm{FC} / \mathrm{O}$ ratio of VTM-CCB on the softening-melting behavior of VTM-CCB/sinter mixtures was explored by conducting softening-melting-dripping (SMD) experiments. Then, the interrupted SMD experiments were carried out to obtain the softening-melting VTM-CCB/sinter mixtures at different temperatures. Finally, the interface behavior and interaction mechanisms between VTM-CCB and sinter during softening-melting process were illustrated by thermodynam- ics calculation and SEM-EDS analyses. The main purpose of the present work is to clarify the softening-melting mechanisms of VTM-CCB/sinter mixtures and provide theoretical basis and technical support for the application of VTM-CCB in BF ironmaking.

\section{Experimental}

\subsection{Raw Materials}

The raw materials used in this study include VTM-CCB, sinter, and coke. The sinter and coke were taken from an Iron\&Steel company in China. The VTM-CCB samples used in the present study was prepared by hot briquetting and heat treatment processes. Firstly, the vanadium titanomagnetite and coal were ground to a particle size of less than $75 \mathrm{um}$. Next, the obtained fine vanadium titanomagnetite and fine coal were mixed uniformly. After that, the mixtures were charged into an ellipsoid die and heated to $200^{\circ} \mathrm{C}$ and briquetted under a pressure of $40 \mathrm{MPa}$ to form briquettes. Then, the briquettes were charged into heat furnace to take heat treatment at $500^{\circ} \mathrm{C}$ for 3 hours. Finally, VTM-CCB samples were taken out from heat furnace and then cooled to room temperature. The proximate analyses and chemical compositions of the coke are listed in Table 1. The chemical compositions of sinter and VTM-CCB with different $\mathrm{FC} / \mathrm{O}$ ratios were listed in Table 2. It should be pointed out that the $\mathrm{FC} / \mathrm{O}$ ratio, calculated by the ratio of the fixed carbon $\operatorname{mol}(\mathrm{C})$ to the reducible oxygen $\operatorname{mol}(\mathrm{O})$ in iron oxides, was set in the range from 0.8 to $1.4(\mathrm{FC} / \mathrm{O}=0.8$, $1.0,1.2,1.4)$. The constituent mineral phases of VTM-CCB are complex, mainly containing magnetite $\left(\mathrm{Fe}_{3} \mathrm{O}_{4}\right)$, titanomagnetite $\left(\mathrm{Fe}_{2.75} \mathrm{Ti}_{0.25} \mathrm{O}_{4}\right)$, ilmenite $\left(\mathrm{FeTiO}_{3}\right)$, and coulsonite $\left(\mathrm{Fe}_{2} \mathrm{VO}_{4}\right)$.

\subsection{Softening-melting-dripping Tests}

The interface behavior and interaction between VTM-CCB and sinter were investigated by conducting softening-melting tests. The softening-melting furnace, as shown in Fig. 1, mainly consists of heat furnace, temperature control system, loading system, and gas control system. The mixed burden of approximately $500 \mathrm{~g}$, containing 20\% (mass) VTM-CCB and 80\% (mass) sinter, was charged into a graphite crucible with a diameter of $75 \mathrm{~mm}$. It should be

Table 1. Proximate analyses and chemical compositions of coke used in softening-melting tests (wt $\%)$

\begin{tabular}{ccccccc}
\hline Fixed Carbon & Ash & Volatiles & $\mathrm{CaO}$ & $\mathrm{SiO}_{2}$ & $\mathrm{Al}_{2} \mathrm{O}_{3}$ & $\mathrm{~S}$ \\
\hline 85.88 & 12.55 & 1.50 & 0.25 & 6.38 & 3.04 & 0.72 \\
\hline
\end{tabular}

Table 2. Chemical compositions of sinter and VTM-CCB with different FC/O ratio (wt \%).

\begin{tabular}{|c|c|c|c|c|c|c|c|c|c|c|}
\hline \multicolumn{2}{|c|}{ Raw materials } & $\mathrm{TFe}$ & $\mathrm{FeO}$ & $\mathrm{CaO}$ & $\mathrm{SiO}_{2}$ & $\mathrm{MgO}$ & $\mathrm{Al}_{2} \mathrm{O}_{3}$ & $\mathrm{TiO}_{2}$ & $\mathrm{~V}_{2} \mathrm{O}_{5}$ & $\mathrm{FC}$ \\
\hline \multicolumn{2}{|c|}{ Sinter } & 53.32 & 7.45 & 12.46 & 5.54 & 3.16 & 2.22 & 1.23 & 0.26 & - \\
\hline \multirow{4}{*}{ VTM-CCB } & $\mathrm{FC} / \mathrm{O} 0.8$ & 52.44 & 24.54 & 0.27 & 2.72 & 0.81 & 3.87 & 4.26 & 0.80 & 11.83 \\
\hline & $\mathrm{FC} / \mathrm{O} 1.0$ & 50.58 & 23.70 & 0.26 & 2.85 & 0.79 & 3.83 & 4.11 & 0.77 & 14.28 \\
\hline & $\mathrm{FC} / \mathrm{O} 1.2$ & 48.91 & 22.92 & 0.29 & 2.97 & 0.78 & 3.79 & 3.98 & 0.75 & 16.57 \\
\hline & $\mathrm{FC} / \mathrm{O} 1.4$ & 47.34 & 22.18 & 0.30 & 3.09 & 0.76 & 3.75 & 3.85 & 0.72 & 18.71 \\
\hline
\end{tabular}




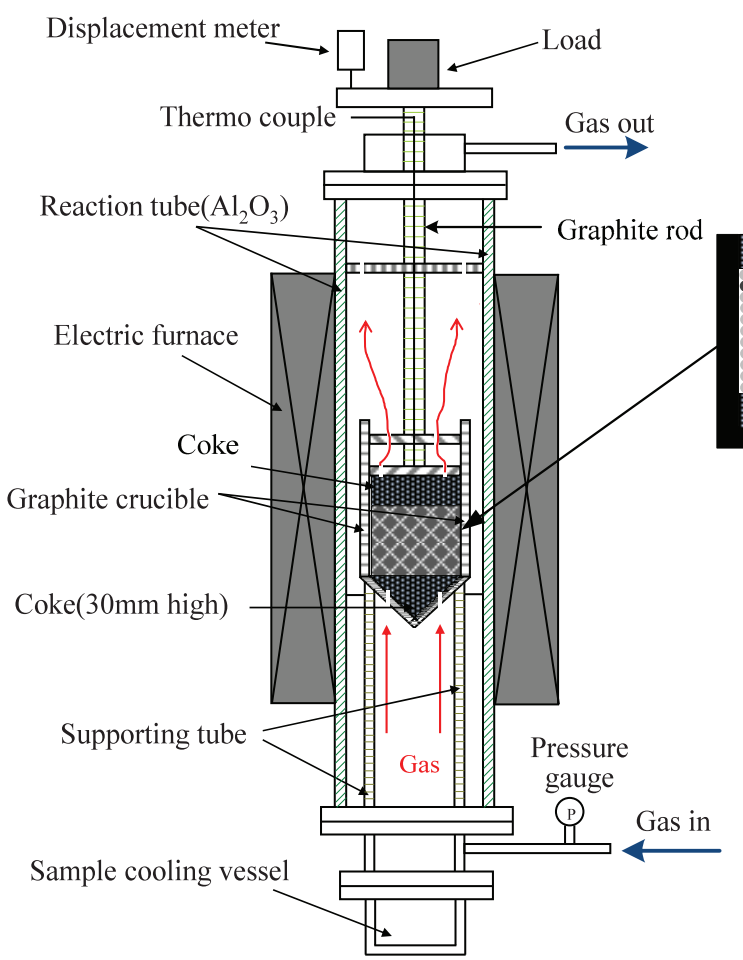

Load: $0.5 \mathrm{~kg} / \mathrm{cm}^{2}$ before $900^{\circ} \mathrm{C} ; 1.0 \mathrm{~kg} / \mathrm{cm}^{2}$ after $900^{\circ} \mathrm{C}$ $\sqrt{4}$ Coke

Over view of graphite crucible

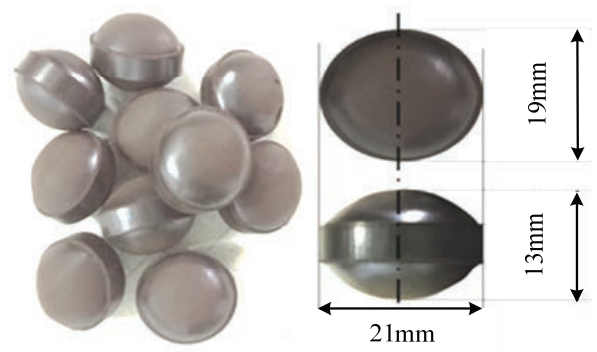

(b) Mopholorgy of VTM-CCB

(a) Softening-melting furnace

Fig. 1. (a) softening-melting furnace and (b) morphology of VTM-CCB. (Online version in color.)

pointed out that the dried sinter with a diameter of 10-12.5 $\mathrm{mm}$ was used in this study. The dried coke with a diameter of 10-12.5 $\mathrm{mm}$ and a layer thickness of $30 \mathrm{~mm}$ and 17 $\mathrm{mm}$ were placed below and over the iron-bearing burden to guarantee the reduction gas passing through and the molten slag-iron mixtures dripping through. The temperature, displacement and pressure drop of the packed bed were detected and recorded automatically during the tests.

The experimental schemes are listed in Table 3. The experimental results represented an average of 3 times measurements. The mixed burden in graphite crucible was heated and reduced with the definite temperature profile, reduction gases and loading profile in different temperature ranges referring to previous researches. ${ }^{31,32)}$ The heating rates were $10^{\circ} \mathrm{C} / \mathrm{min}$ in the temperature range below $900^{\circ} \mathrm{C}$, $3{ }^{\circ} \mathrm{C} / \mathrm{min}$ in the range from $900^{\circ} \mathrm{C}$ to $1020^{\circ} \mathrm{C}$, and $5^{\circ} \mathrm{C} / \mathrm{min}$ in the range from $1020^{\circ} \mathrm{C}$ to the end. The gas flow was 3 $\mathrm{L} / \mathrm{min}$ of $\mathrm{N}_{2}$ in the temperature range below $400^{\circ} \mathrm{C} ; 9 \mathrm{~L} / \mathrm{min}$ of $\mathrm{N}_{2}, 3.9 \mathrm{~L} / \mathrm{min}$ of $\mathrm{CO}$, and $2.1 \mathrm{~L} / \mathrm{min}$ of $\mathrm{CO}_{2}$ from $400^{\circ} \mathrm{C}$ to $900^{\circ} \mathrm{C}$; and $10.5 \mathrm{~L} / \mathrm{min}$ of $\mathrm{N}_{2}$ and $4.5 \mathrm{~L} / \mathrm{min}$ of $\mathrm{CO}$ from $900^{\circ} \mathrm{C}$ to the end of the experiment. The load was put on the pressure rod and then delivered to the sample, as shown in Fig. 3. During the softening-melting-dripping tests, the load on the sample was $0.5 \mathrm{~kg} / \mathrm{cm}^{2}$ at temperatures below $900^{\circ} \mathrm{C}$, and increased to then it is $1.0 \mathrm{~kg} / \mathrm{cm}^{2}$ when the temperature was exceeds $900^{\circ} \mathrm{C}$ or greater.

To better understand the interaction mechanism between VTM-CCB and sinter, a series of interrupted softening-melting tests were also conducted. During softening-melting experiment, the gas supply and power supply were stopped immediately when the temperature of packed bed reached the pre-set value $\left(1200^{\circ} \mathrm{C}, 1300^{\circ} \mathrm{C}\right.$, and $1400^{\circ} \mathrm{C}$ ), and the nitrogen gas with a flow rate of 5 $\mathrm{NL} / \mathrm{min}$ was introduced to the reaction tube to cool down
Table 3. Scheme of softening-melting experiments.

\begin{tabular}{ccccc}
\hline Case & Sinter/wt\% & VTM-CCB/wt\% & $\begin{array}{c}\text { FC/O ratio of } \\
\text { VTM-CCB/- }\end{array}$ & Total mass/g \\
\hline 1 & $100 \%$ & 0 & - & 500 \\
2 & $80 \%$ & $20 \%$ & 0.8 & 500 \\
3 & $80 \%$ & $20 \%$ & 1.0 & 500 \\
4 & $80 \%$ & $20 \%$ & 1.2 & 500 \\
5 & $80 \%$ & $20 \%$ & 1.4 & 500 \\
\hline
\end{tabular}

the mixed burden and to discharge the reduction gas as soon as possible. After cooling down to room temperature, the mixed burden was cut into two pieces, and then the crosssections were scanned by SEM-EDS method.

\subsection{Characterization Methods}

2.3.1. Instrumental Analyses

For the morphology analysis, the interface between sinter and VTM-CCB were observed by scanning electron microscopy (SEM, Jena, Germany) with energy dispersive X-ray spectroscopy (EDS). The interface layer was observed by SEM-EDS to elucidate intrinsic morphology evolution and interactions during softening-melting process.

To explore the slag melting temperature and liquid slag generation proportion in different cases, the $\mathrm{FeO}$ concentration was detected by titration method with potassium dichromate solution. Notably, the titration process of $\mathrm{FeO}$ was conducted in $\mathrm{HCl}$ solution under $\mathrm{CO}_{2}$ gas atmosphere. According to the chemical analysis results, the thermodynamics calculations, including phase diagram drawing and equilibrium phase components, were conducted by Factsage 7.0 software. 


\subsubsection{Softening-melting Indexes}

To evaluate the softening-melting-dripping behavior of VTM-CCB/sinter mixtures, some characteristic temperatures were defined in this research. $T_{4}$, the temperature at which the contraction of the packed bed reaches $4 \%$, is defined as the softening start temperature because the contraction of the packed bed notably rises when the temperature reaches $T_{4}$. When the contraction of packed bed reaches approximately $40 \%$, the iron-bearing particles gradually bond to form a denser structure, which results in an increase in the pressure drop across the packed bed. ${ }^{33)}$ Therefore, $T_{40}$, the temperature at which the contraction of the packed bed reaches $40 \%$, is defined as the softening end temperature. With further increases in temperature, the iron-bearing packed bed starts melting, and the contraction continues rising steeply. As the melting occurs, the gas permeability would noticeably deteriorate. Therefore, the temperature associated with a substantial increase in pressure drop is defined as the melting start temperature $T_{\mathrm{S}}{ }^{32,33)}$ The dripping temperature $T_{\mathrm{D}}$ is the temperature at which the pig iron starts to drip from the graphite crucible.

\section{Results and Discussion}

\subsection{Softening-melting Behaviors of VTM-CCB/sinter Mixtures}

The softening behaviors of mixed burden at different cases were presented in Fig. 2. With increasing the $\mathrm{FC} / \mathrm{O}$ ratio of charged VTM-CCB, $T_{4}$ decreased from $1133.8^{\circ} \mathrm{C}$ to $1099.8^{\circ} \mathrm{C}$ firstly and then gradually increased to $1112.1^{\circ} \mathrm{C}$, and $T_{40}$ decreased from $1270.5^{\circ} \mathrm{C}$ to $1257.8^{\circ} \mathrm{C}$ firstly and then increased to $1280.9^{\circ} \mathrm{C}$. The softening temperature range $\left(T_{40}-T_{4}\right)$ widened gradually with increasing $\mathrm{FC} / \mathrm{O}$ ratio. In general, the wider range of $\left(T_{40}-T_{4}\right)$ favors to the gas-solid reduction of iron-bearing burden. ${ }^{34)}$

To illustrate the tendency of the $T_{4}$ and $T_{40}$, the softening VTM-CCB/sinter mixtures interrupted at $1200^{\circ} \mathrm{C}$ were analyzed by SEM-EDS. A bonding layer could be observed clearly at the interface between VTM-CCB $(\mathrm{FC} / \mathrm{O}=0.8)$ and sinter, as shown in Fig. 3(a). It could be deduced from the different basicity of sinter/VTM-CCB mixtures and calcium distribution image, the left side of the interface is sinter and the right side is VTM-CCB. Based on EDS and stoichiometric analyses, the interface in Fig. 3(b) mainly consists

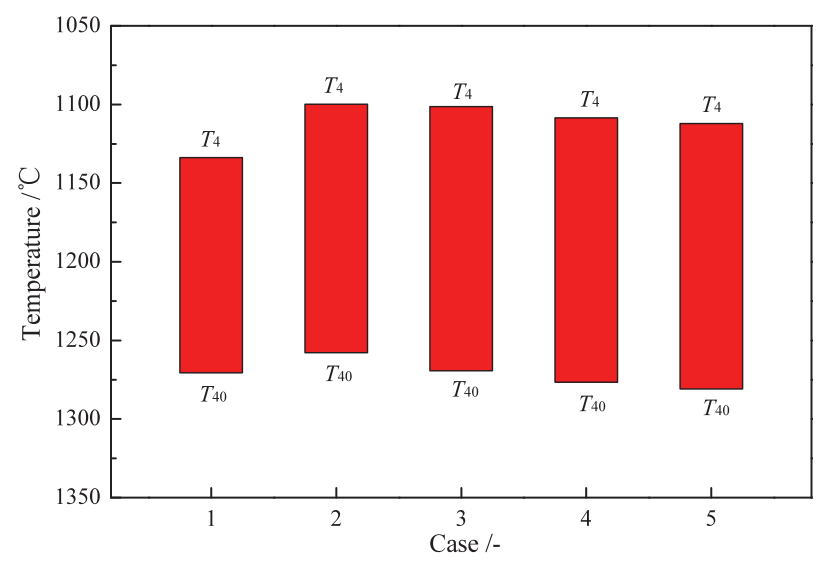

Fig. 2. Softening start and end temperatures of VTM-CCB/sinter mixtures at different cases. (Online version in color.) of metallic iron, perovskite and melilite slag phases. In the VTM-CCB areas away from the interface in Fig. 3(c), the main components include metallic iron, $\mathrm{Fe}-\mathrm{Mg}-\mathrm{Al}$ composite spinel, $\mathrm{Fe}-\mathrm{Al}-\mathrm{Si}$ composite pyroxene, and $\mathrm{Ti}-\mathrm{Fe}$ iron oxides. In the sinter areas away from the interface in Fig. 3(d), the main components include metallic iron, $\mathrm{Fe}-\mathrm{Mg}$ spinel and melilite slag phase. Clearly, the amount of molten slag appeared in the interface is more than that in the other areas, which indicates the interface bonding behavior would promote the softening and shrinking of mixtures, thereby decreasing $T_{4}$ and $T_{40}$. With increasing the $\mathrm{FC} / \mathrm{O}$ ratio to 1.0 , the interface between VTM-CCB and sinter, as shown in Figs. 3(e)-3(f), mainly consists of metallic iron, Ti-Fe iron oxides, $\mathrm{Ca}_{2} \mathrm{SiO}_{4}$, and melilite slag phase. In the VTM$\mathrm{CCB}$ and sinter areas away from the interface in Figs. 3(g)3(h), the main components are consistent with that in Figs. 3(c)-3(d). Based on the elemental distribution images, the left side of the interface is VTM-CCB and the right side is sinter. It can be observed that the amount of molten slag in the bonding layer decreased and the metallic iron increased obviously compared with the bonding layer in Fig. 3(a). Due to the metallic iron joined crystal performing a relative high strength, the softening and shrinking of the VTM-CCB/sinter mixtures were suppressed. As a result, the bonding behavior between VTM-CCB and sinter alleviated, and the $T_{4}$ and $T_{40}$ increased in this case. With further increases in the $\mathrm{FC} / \mathrm{O}$ ratio of VTM-CCB, the excessive carbon would hinder the bonding between sinter and VTM-CCB, as shown in Fig. 3(i). The interface of sinter and VTM-CCB kept their own characteristics without bonding at $1200^{\circ} \mathrm{C}$. Besides, though the sinter gradually softening due to the molten slag formation in Fig. 3(k), the VTM-CCB, acting as skeleton in Fig. $3(j)$, could alleviate the shrinking of sinter effectively. As a result, the $T_{4}$ and $T_{40}$ increased obviously.

Figure 4 shows the melting-dripping temperatures of VTM-CCB/sinter mixtures at different cases. It can be seen that the $T_{\mathrm{S}}$ increased from $1297.9^{\circ} \mathrm{C}$ to $1326.7^{\circ} \mathrm{C}$ gradually, and the $T_{\mathrm{D}}$ decreased from $1510.0^{\circ} \mathrm{C}$ to $1468.6^{\circ} \mathrm{C}$ firstly then increased to $1499.8^{\circ} \mathrm{C}$. The melting temperature range $\left(T_{\mathrm{D}}-T_{\mathrm{S}}\right)$, namely, the cohesive zone, shifted down gradually, and its size narrowed firstly and then widened. In general, minimizing the size and lowering the position of cohesive zone could improve the gas permeability and the productivity of BF. Therefore, the melting performance and cohesive zone of VTM-CCB/sinter mixtures could be improved by selecting an appropriate $\mathrm{FC} / \mathrm{O}$ ratio of VTM-CCB.

The melting performances of iron-bearing burden correlated to the structure transition during melting process. Figure 5 shows the SEM-EDS analyses of the sample in different cases interrupted at $1300^{\circ} \mathrm{C}$. As shown in Fig. 5 (b), the serious dispersion of the molten iron and slag would block the reduction gas passing through and deteriorate the reduction of iron oxides. Based on the EDS results, the melting sinter mainly consists of metallic iron, wustite, perovskite, $\mathrm{CaSiO}_{3}$ and melilite slag phases, as shown in Fig. 5(c). It should be pointed out that large amounts wustite phases existed at the interface between metallic iron and slag, which would accelerate the formation of low melting point slag, thereby promoting the melting of sinter and decreasing the $T_{\mathrm{s}}$. In case 2, a bonding layer could be observed clearly between VTM-CCB and sinter, as shown 

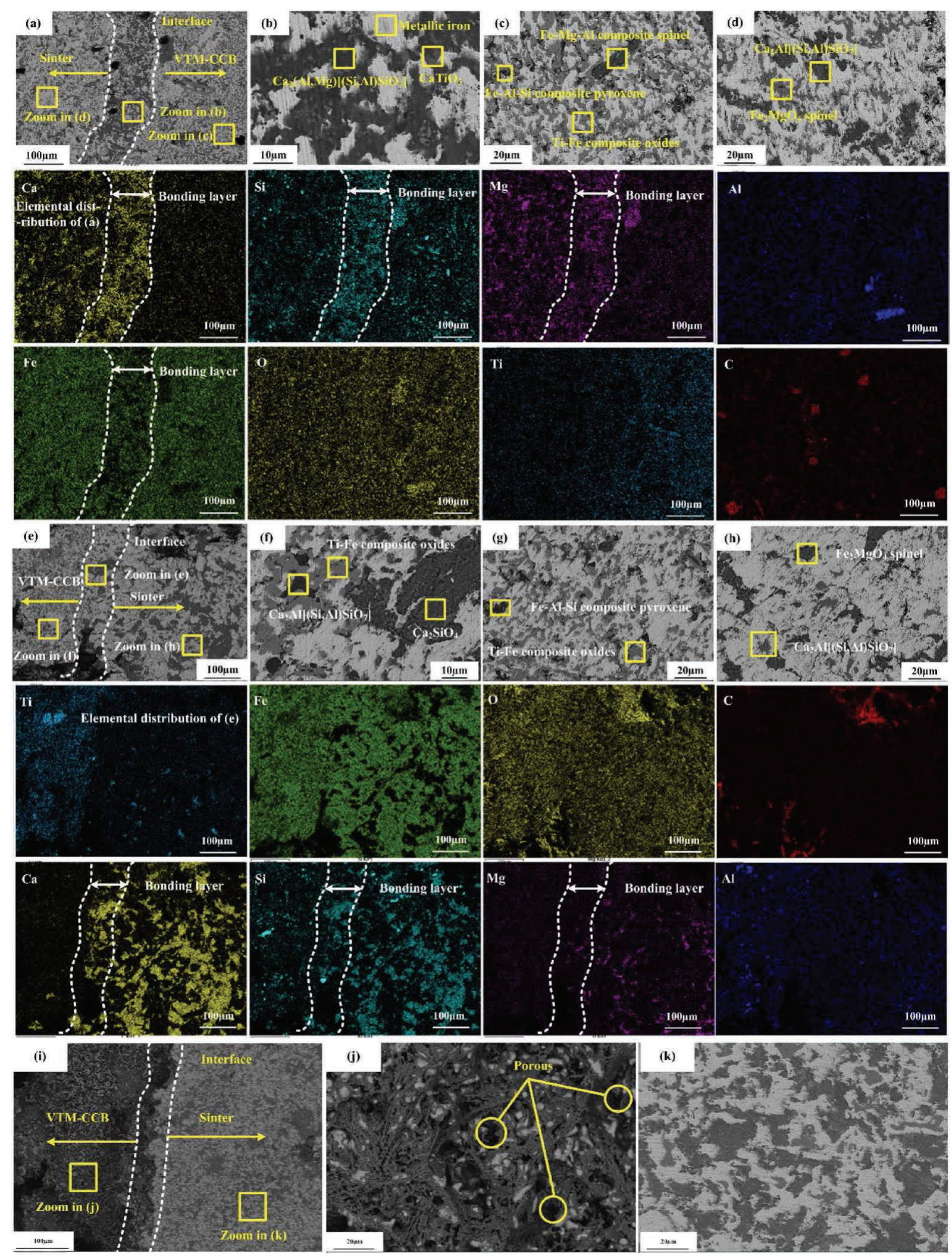

Fig. 3. SEM-EDS analyses of the interface at $1200^{\circ} \mathrm{C}$ between sinter and VTM-CCB with different FC/O ratio: (a, b, c, d) $\mathrm{FC} / \mathrm{O}=0.8$, (e, f, g, h) $\mathrm{FC} / \mathrm{O}=1.0$, and $(\mathrm{i}, \mathrm{j}, \mathrm{k}) \mathrm{FC} / \mathrm{O}=1.4$. (Online version in color.)

in Fig. 5(d). The EDS results in Fig. 5(f) indicated that the bonding layer mainly consists of metallic iron, wustite, and molten slag. The molten slag generated in the sinter gradually diffused to the interface, which could be observed from the calcium concentration gradient at the interface. Additionally, the high-reducibility of VTM-CCB would promote the reduction of iron oxides in the sinter areas near the inter- face. As shown in Fig. 5(g), in the sinter areas away from the interface, the main components are $\mathrm{Fe}-\mathrm{Mg}$ composite oxides and silicate slag, and in the areas near the interface, large amounts of metallic iron appeared in the sinter. As a result, the bonding layer presented as metal-slag coexisting mixed structure. Besides, the reduction promotion of sinter could decrease the wustite phase and suppress the formation 
of low melting point slag at the interface. Therefore, the melting behavior of the sinter/VTM-CCB mixtures would be alleviated and the $T_{\mathrm{s}}$ would be increased obviously. With increasing the $\mathrm{FC} / \mathrm{O}$ ratio to 1.4 , as shown in Fig. 5(i), the

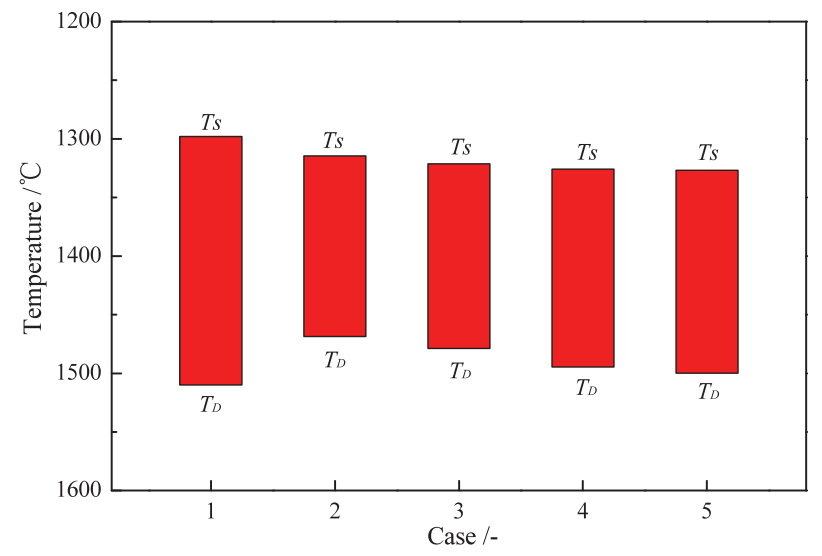

Fig. 4. Melting-dripping temperatures of VTM-CCB/sinter mixtures at different cases. (Online version in color.) excessive carbon in VTM-CCB would promote the reduction of sinter effectively. The molten slag in the interface layer decreased steeply and the interface transformed from metal-slag coexisting mixed structure to dense metallic iron shell, as shown in Fig. 5(j). As a result, the bonding behavior between VTM-CCB and sinter alleviated significantly and $T_{\mathrm{s}}$ increased obviously. Due to a relative high strength of metallic iron shell, the melting and shrinking of VTM-CCB/sinter mixtures would be restricted and the $T_{\mathrm{s}}$ would be increased.

To explore the slag liquid temperature and liquid slag generation ratio in different cases, the $\mathrm{FeO}$ content of the sinter interrupted at $1300^{\circ} \mathrm{C}$ was detected. Then, based on the $\mathrm{FeO}$ content in different cases, the slag liquid temperatures were calculated by Factsage 7.0. As shown in Fig. 6(a), the FeO content decreased obviously because the reduction of sinter was promoted by increasing the $\mathrm{FC} / \mathrm{O}$ ratio of $\mathrm{VTM}-\mathrm{CCB}$, and the primary slag liquid temperature increased gradually. The effect of temperature and $\mathrm{FeO}$ content on the liquid slag generation ratio was calculated by Equilibrium model in Factsage 7.0. As shown in Fig.
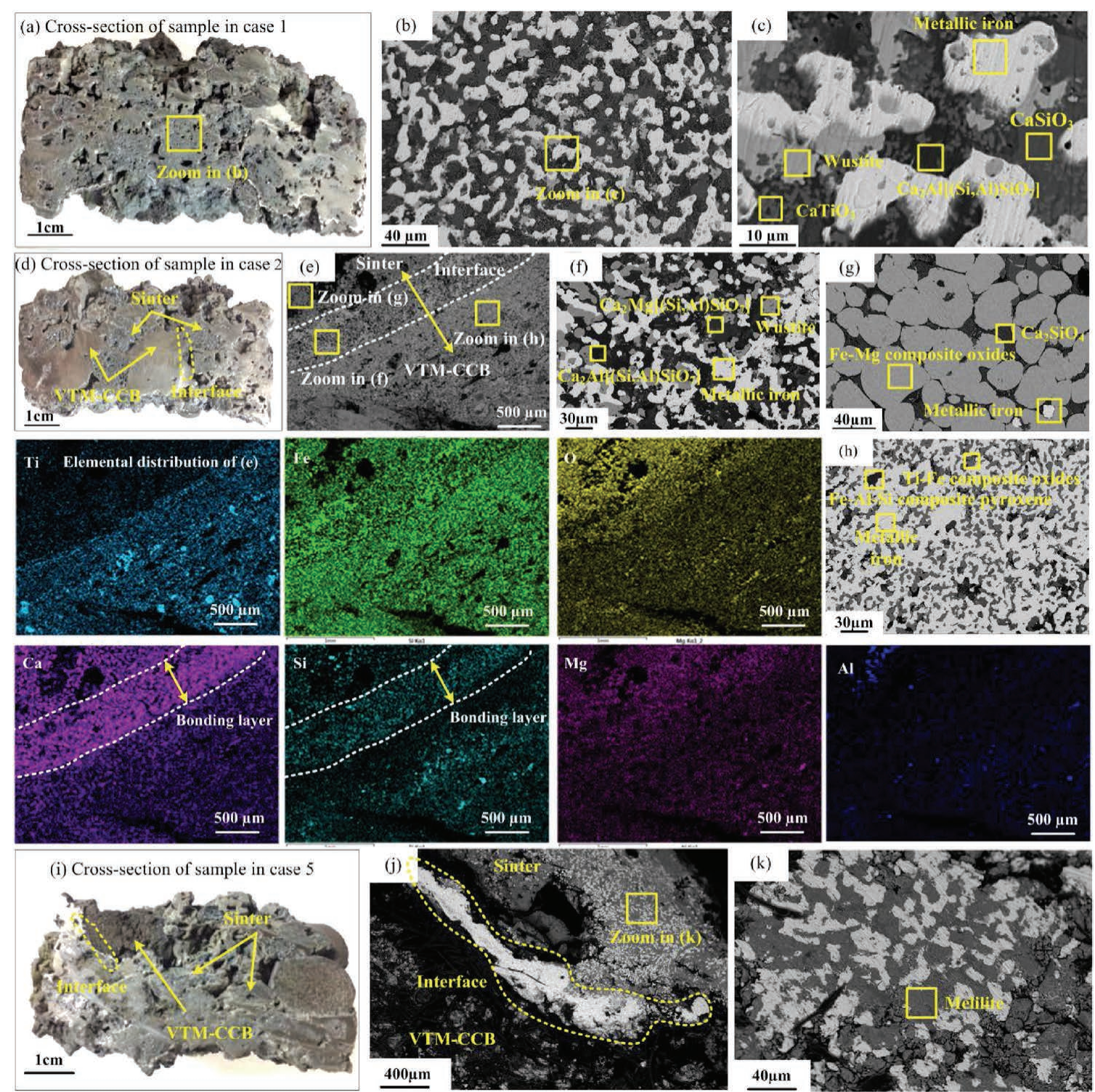

Fig. 5. SEM-EDS analyses of the interface at $1300^{\circ} \mathrm{C}$ between sinter and VTM-CCB with different FC/O ratio: (a, b, c) single sinter without VTM-CCB charging, $(\mathrm{d}, \mathrm{f}, \mathrm{g}, \mathrm{h}) \mathrm{FC} / \mathrm{O}=0.8$, and $(\mathrm{i}, \mathrm{j}, \mathrm{k}) \mathrm{FC} / \mathrm{O}=1.4$. (Online version in color.) 



Fig. 6. (a) FeO content and slag liquidus temperature of the sinter in different cases, and (b) Effect of temperature and $\mathrm{FeO}$ content on the liquid slag generation ratio. (Online version in color.)
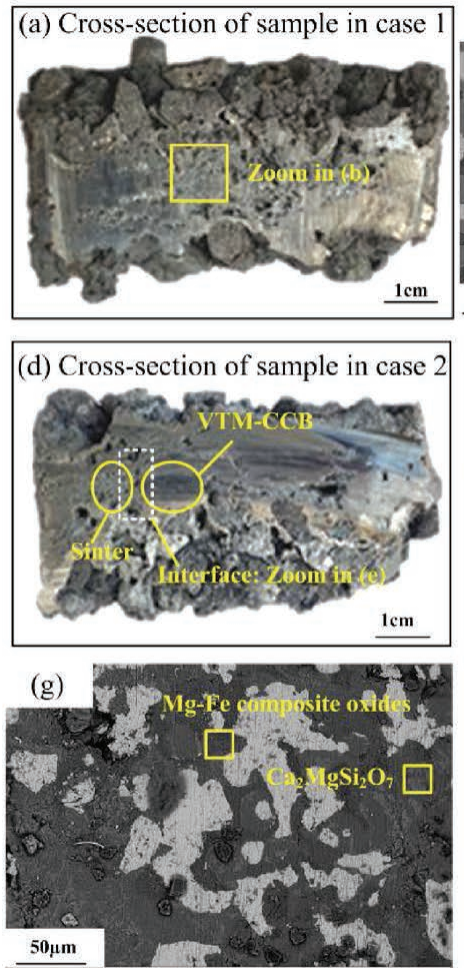
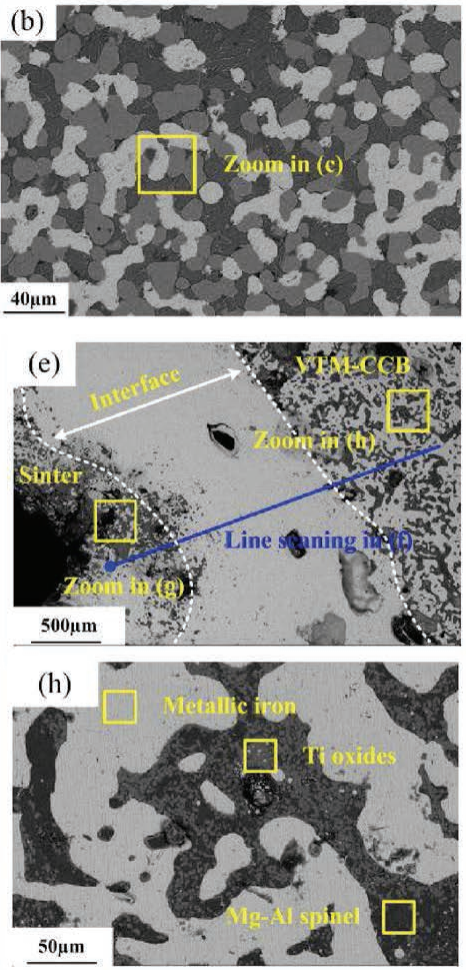
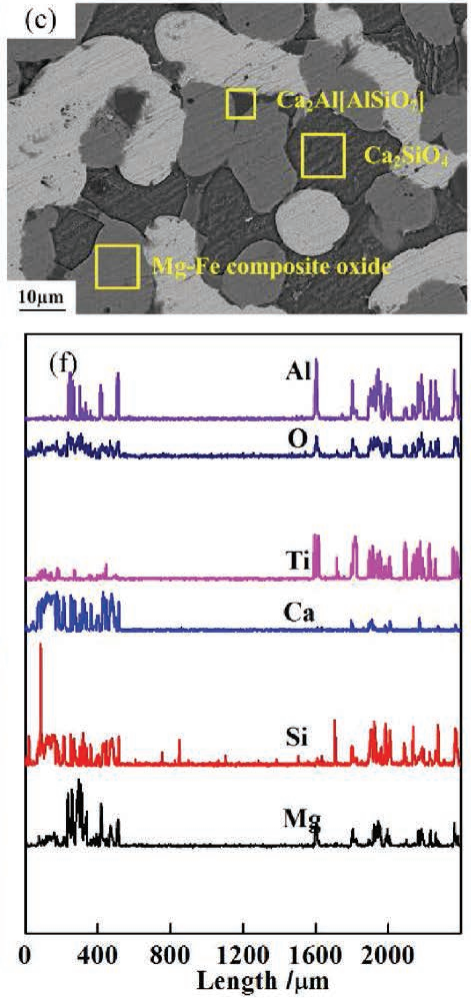

Fig. 7. SEM-EDS analyses of the interface at $1400^{\circ} \mathrm{C}$ between sinter and VTM-CCB with different $\mathrm{FC} / \mathrm{O}$ ratio: (a, b, c) single sinter without VTM-CCB charging, and (e, f) $\mathrm{FC} / \mathrm{O}=0.8$. (Online version in color.)

6(b), the liquid slag proportion decreased obviously with decreasing $\mathrm{FeO}$ content when the temperature was constant. The decreasing of liquid slag could delay the melting of VTM-CCB/sinter mixtures, thereby lowering the position of cohesive zone and benefiting the BF operation.

\subsection{Dripping Characteristics and Interface Behaviors of VTM-CCB/sinter Mixtures}

With further increasing the temperature, the molten iron and slag begin to aggregate respectively and then separate and drip. Figures 7(a)-7(c) present the SEM-EDS analyses of the single sinter interrupted at $1400^{\circ} \mathrm{C}$. As shown in Fig. 7(c), the molten mixtures consists of metallic iron, iron oxides, and silicate slag. Due to the relative poor reducibility of single sinter, large amounts iron oxides existed and distributed in slag and metallic iron, as shown in Fig. 7(b), which restricts the aggregation of molten iron and slag.
Therefore, the dripping of molten iron-slag mixtures are difficult, manifesting in high dripping temperature $T_{\mathrm{D}}$. Figures 7(d)-7(h) show the SEM-EDS analyses of the interface between VTM-CCB $(\mathrm{FC} / \mathrm{O}=0.8)$ and sinter interrupted at $1400^{\circ} \mathrm{C}$. As shown in Fig. 7(d), the VTM-CCB and sinter were directly welded into a whole at $1400^{\circ} \mathrm{C}$. Based on the elemental line scaning results in Figs. 7(e) and 7(f), it can be deduced that the bottom left areas of the interface is sinter, and the upper right area of the interface is VTM-CCB. In the sinter areas away from the interface, as shown in Fig. 7(g), the $\mathrm{Mg}-\mathrm{Fe}$ composite oxides, metallic iron and silicate slag mixed homogeneously, which results in the aggregation of molten iron and slag was suppressed. In the VTM-CCB areas away from the interface, as shown in Fig. 7(h), the molten slag, mainly consists of titanium oxides and silicate slag. Especially, the assemblage of the molten iron in the bonding layer was promoted obviously due to the carburi- 
zation strengthen by VTM-CCB. As a result, the dripping performance of the VTM-CCB/sinter mixtures improved and $T_{\mathrm{D}}$ decreased.

With increasing the $\mathrm{FC} / \mathrm{O}$ ratio to 1.0 , the VTM-CCB and sinter also welded into a whole, as shown in Fig. 8(b), and the interface mainly consists of molten iron and bits of slag. In the sinter area away from the interface, as shown in Fig. 8 (c), the aggregation of iron was more pronounced than that in Fig. 7(g) due to the higher FC/O ratio of VTM-CCB promoting the carburization of iron. However, a higher reduction potential would promote the reduction of titanium iron oxides and accelerate the precipitation of $\mathrm{Ti}(\mathrm{C}, \mathrm{N})$. As shown in Fig. $8(\mathrm{~d})$, the $\mathrm{Ti}(\mathrm{C}, \mathrm{N})$ began to precipitated on the surface of metallic iron. It is well known that $\operatorname{Ti}(\mathrm{C}, \mathrm{N})$ solid particles have a substantial impact on the viscosity of slag and iron once they enter into the molten phases. ${ }^{39,40)}$ The viscosity of the molten phases increased sharply with the formation of $\operatorname{Ti}(\mathrm{C}, \mathrm{N})$, thereby increasing the dripping temperature $T_{\mathrm{D}}$.

With further increasing the $\mathrm{FC} / \mathrm{O}$ ratio to 1.4 , large amounts residual carbon particles could be observed in VTM-CCB, as shown in Fig. 9(a), which would suppress the bonding behavior between VTM-CCB and sinter seriously, as shown in Fig. 9(b). Due to the excessive carbon in VTM-CCB, the $\mathrm{Ti}(\mathrm{C}, \mathrm{N})$ particles precipitated on the surface of iron particles in VTM-CCB, as shown in Fig. 9(d). Besides, large amounts $\mathrm{Ti}(\mathrm{C}, \mathrm{N})$ particles precipitated in the sinter area near the interface, as shown in Fig. 9(c). Based on the higher magnification BSE image shown in Fig. 9(e) and the elemental mapping distribution, the $\mathrm{Ti}(\mathrm{C}, \mathrm{N})$ mainly precipitated at the interface between molten iron and slag, which matches well with the description in the previous literatures. ${ }^{35-37)}$ The $\mathrm{Ti}(\mathrm{C}, \mathrm{N})$ solid particles have a great impact on the viscosity of slag once they entered into the molten phases (slag and metal). The viscosity of slag would
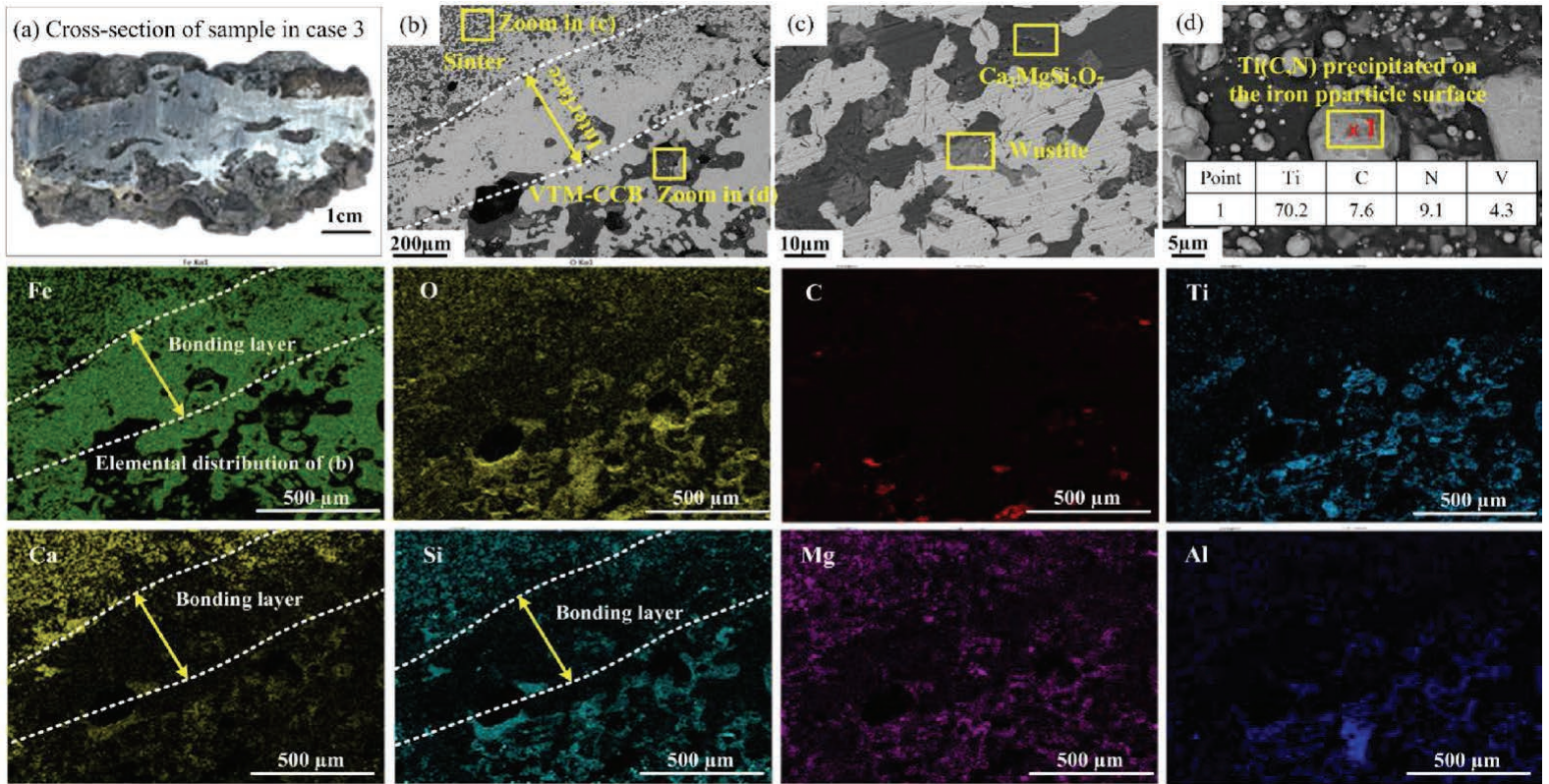

Fig. 8. SEM-EDS analyses of the interface between $\mathrm{VTM}-\mathrm{CCB}(\mathrm{FC} / \mathrm{O}=1.0)$ and sinter interrupted at $1400^{\circ} \mathrm{C}$. (Online version in color.)
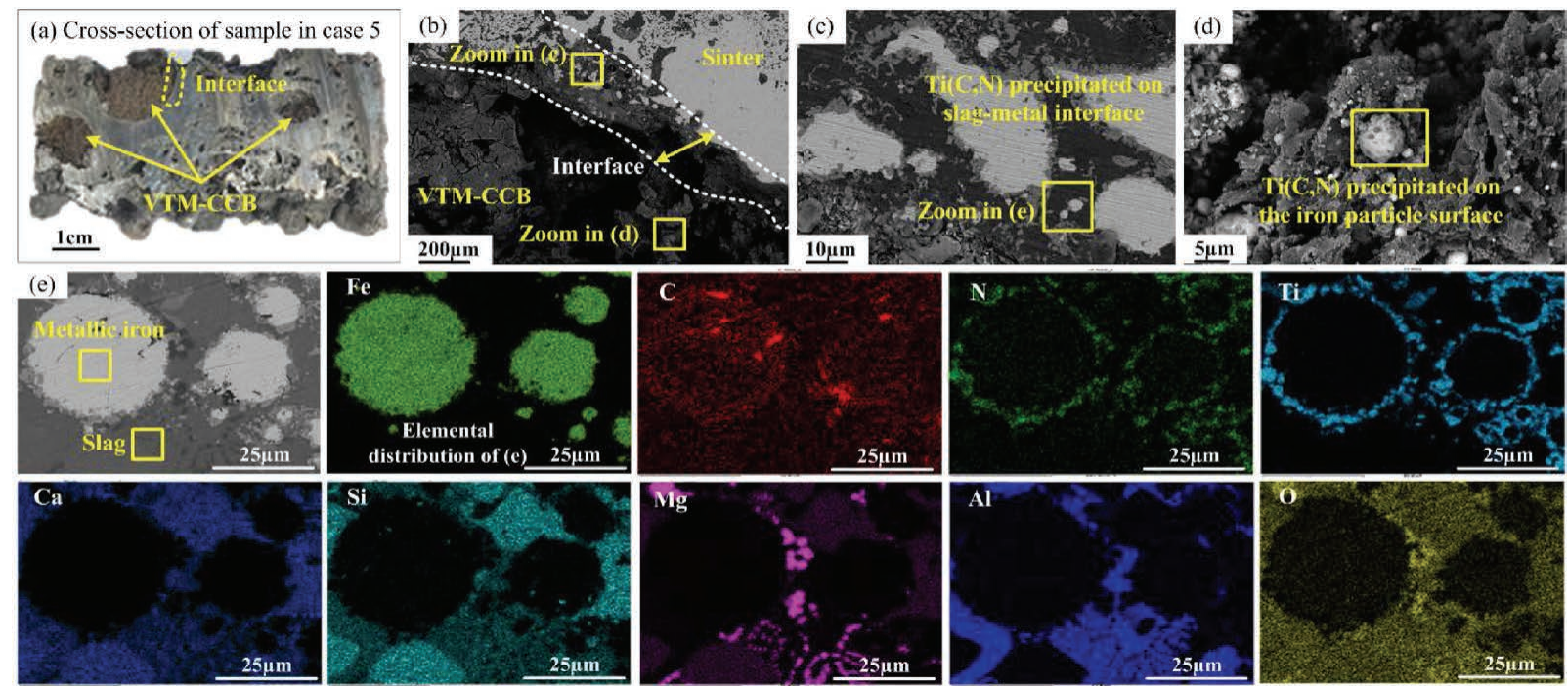

Fig. 9. SEM-EDS analyses of the interface between $\mathrm{VTM}-\mathrm{CCB}(\mathrm{FC} / \mathrm{O}=1.4)$ and sinter interrupted at $1400^{\circ} \mathrm{C}$. (Online version in color.) 
be increased sharply with the formation of $\operatorname{Ti}(\mathrm{C}, \mathrm{N})$. Besides, as solid dispersed phase in slag, $\operatorname{Ti}(\mathrm{C}, \mathrm{N})$ would increase the internal friction of the suspension slag system, thus thickening the slag, which would increase the $T_{\mathrm{D}}$ steeply and deteriorate the dripping behavior of the slag and iron mixture. ${ }^{38-40)}$ Therefore, to suppress the precipitation of the $\mathrm{Ti}(\mathrm{C}, \mathrm{N})$ and guarantee the dripping performance of the molten mixtures, the $\mathrm{FC} / \mathrm{O}$ ratio of charged VTM-CCB should be controlled in a rational range.

\subsection{Interactions between VTM-CCB and Sinter}

The softening-melting characteristics of VTM-CCB/sinter mixtures correlated to the interface structures and phase components. Figure 10 presents the schematic diagram and $\mathrm{BSE}$ images of the interface structure evolution between VTM-CCB and sinter at different cases. With a FC/O ratio of 0.8 , the interface transformed from molten slag-metal coexisting structure to metal structure with enhancing temperature from $1200^{\circ} \mathrm{C}$ to $1400^{\circ} \mathrm{C}$. Simultaneously, the thickness of the bonding layer increased obviously. The slag-metal coexisting structure at the interface would accelerate the bonding and softening process. With a $\mathrm{FC} / \mathrm{O}$ ratio of 1.4 , there was no bonding layer observed at the pre-set temperatures. At $1300^{\circ} \mathrm{C}$, the interface of sinter performed as density metallic iron shell, which is mainly due to the strengthening reduction by the excessive carbon in VTM-CCB. Further increasing the temperature to $1400^{\circ} \mathrm{C}$, the interface at the sinter appeared as slag-metal coexisting structure due to the precipitated $\mathrm{Ti}(\mathrm{C}, \mathrm{N})$ worsening the conglomeration of molten slag and iron, which would deteriorate the dripping behavior. However, the appropriate increasing of the $\mathrm{FC} / \mathrm{O}$ ratio could suppress the bonding structure formation between VTM-CCB and sinter, which benefits the gas permeability of packed bed in the softeningmelting process.

The interface structure between VTM-CCB and sinter could be attributed to the reaction and phase components transition during softening-melting process. As abovementioned, the interface structure mainly included slag-metal coexisting structure in case 2 and case 3 . Therefore, the phase diagram was introduced to illustrate the slag phase transition in this study. Figure 11 presents the $\mathrm{CaO}-\mathrm{SiO}_{2}-$ $\mathrm{MgO}-\mathrm{Al}_{2} \mathrm{O}_{3}$ quaternary phase diagram and the interactions between VTM-CCB and sinter in case 1-3. Based on the chemical compositions of raw materials and EDS results of interface area (case 2-3), the sinter, VTM-CCB, and interface areas located in the monoxide, mullite, and melilite zone, respectively. The isothermal line indicates the melting point of the interface area slag phase is relative lower than that of the initial slag phase in VTM-CCB and sinter. This indicates the interface slag formation between VTM-CCB and sinter could promote the softening and shrinking of the mixtures. Combining the elemental distribution images in Figs. 4 and 5, the interface slagging behavior could be divided into 2 steps. In step 1, the $\mathrm{SiO}_{2}$ in VTM-CCB reacted with $\mathrm{CaO}, \mathrm{Al}_{2} \mathrm{O}_{3}$ and $\mathrm{FeO}$ at the sinter interface to form molten slag, which results in the bonding layer appeared. In this step, the concentration gradient of $\mathrm{SiO}_{2}\left(\mathrm{D}_{1} \mathrm{~B}_{1}\right)$ was
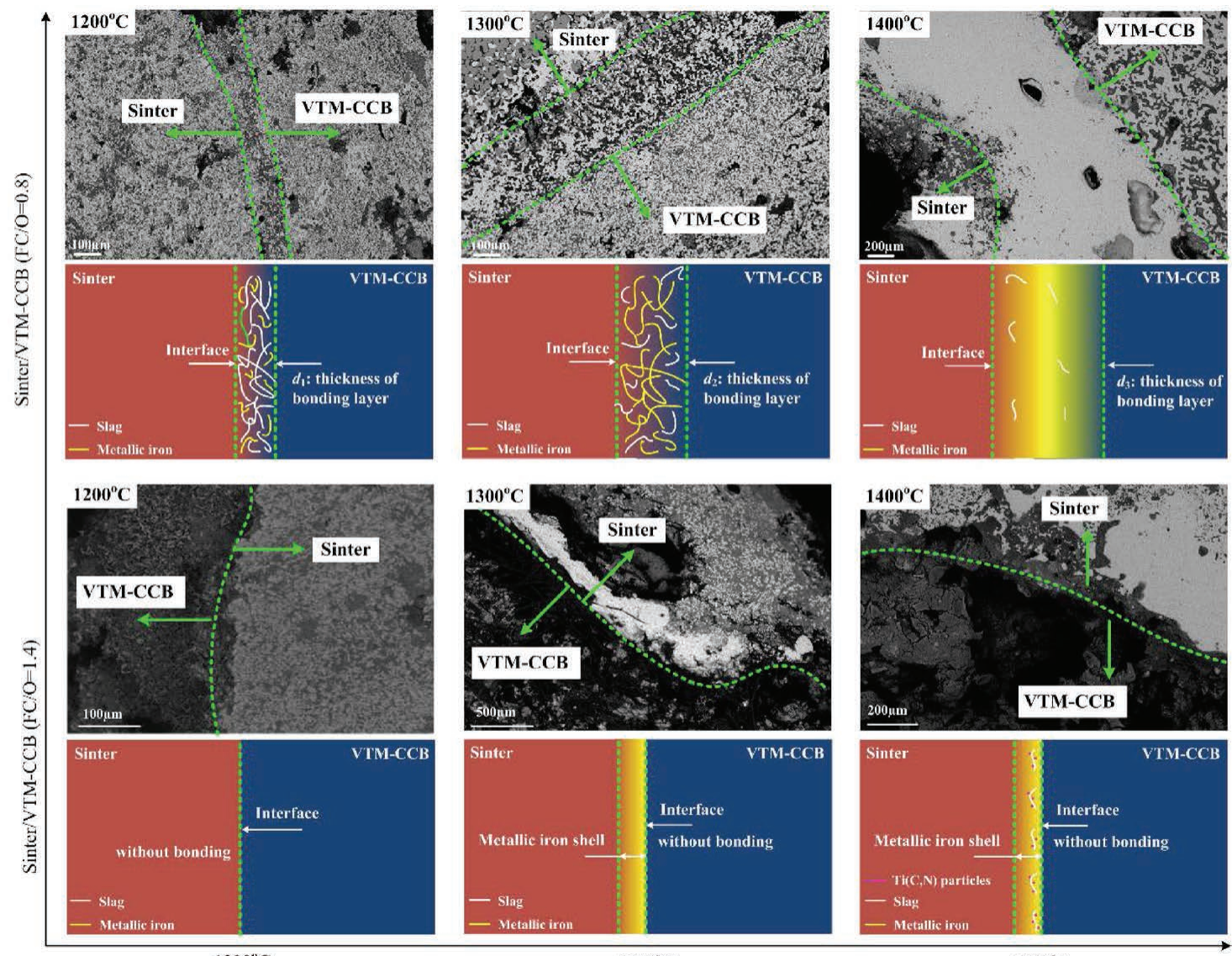

$1300^{\circ} \mathrm{C}$

$1400^{\circ} \mathrm{C}$

Fig. 10. Schematic diagram and BSE images of the interface between VTM-CCB and sinter at different cases. (Online version in color.) 


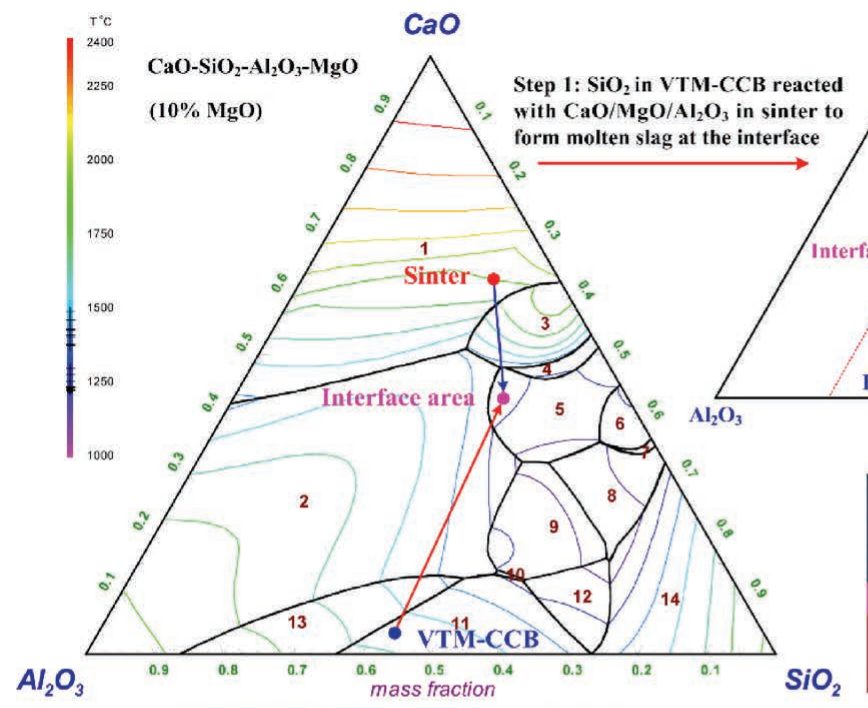

(a) $\mathrm{CaO}-\mathrm{SiO}_{2}-\mathrm{Al}_{2} \mathrm{O}_{3}-\mathrm{MgO}$ phase diagram

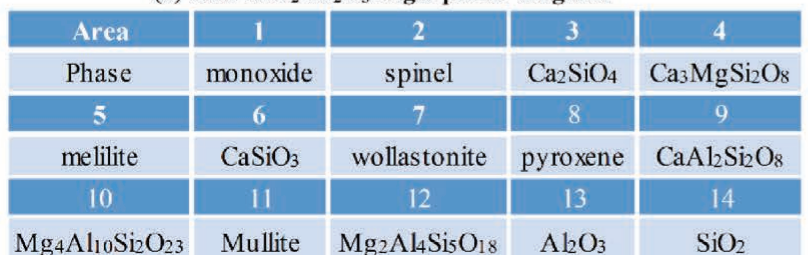

\begin{tabular}{|l|l|l|l|l}
$\mathrm{Mg}_{4} \mathrm{Al}_{10} \mathrm{Si}_{2} \mathrm{O}_{23}$ & Mullite & $\mathrm{Mg}_{2} \mathrm{Al}_{4} \mathrm{Si}_{5} \mathrm{O}_{18}$ & $\mathrm{Al}_{2} \mathrm{O}_{3}$ & $\mathrm{SiO}_{2}$
\end{tabular}

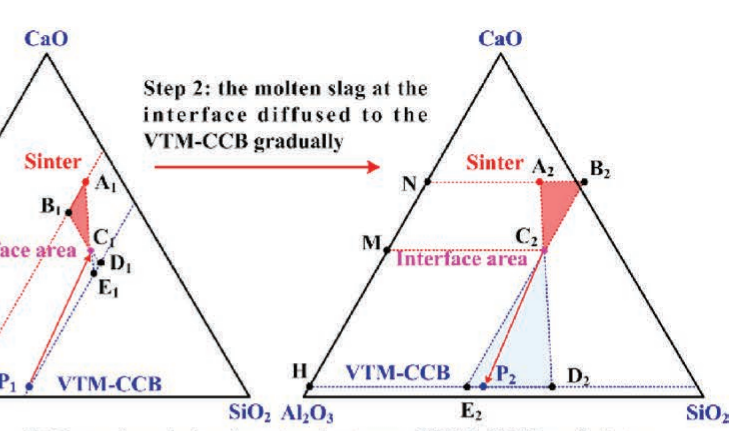

(b) Interface behavior step between VTM-CCB and sinter

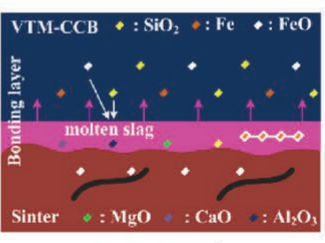

Case $2-1200^{\circ} \mathrm{C}$

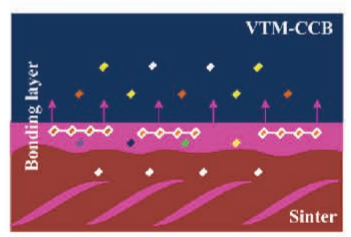

Case $2-1300^{\circ} \mathrm{C}$

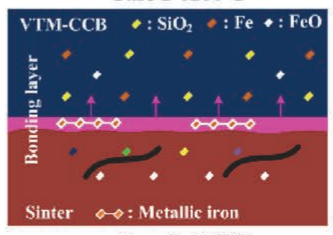

Case $3-1200^{\circ} \mathrm{C}$

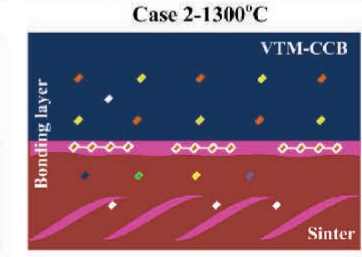

Case $3-1300^{\circ} \mathrm{C}$

(c) Interactions between VTM-CCB and sinter in case 2 3

Fig. 11. (a) $\mathrm{CaO}-\mathrm{SiO}_{2}-\mathrm{Al}_{2} \mathrm{O}_{3}-\mathrm{MgO}$ phase diagram, (b) interface behavior step between VTM-CCB and sinter, and (c) interactions between VTM-CCB and sinter in case 2-3. (Online version in color.)

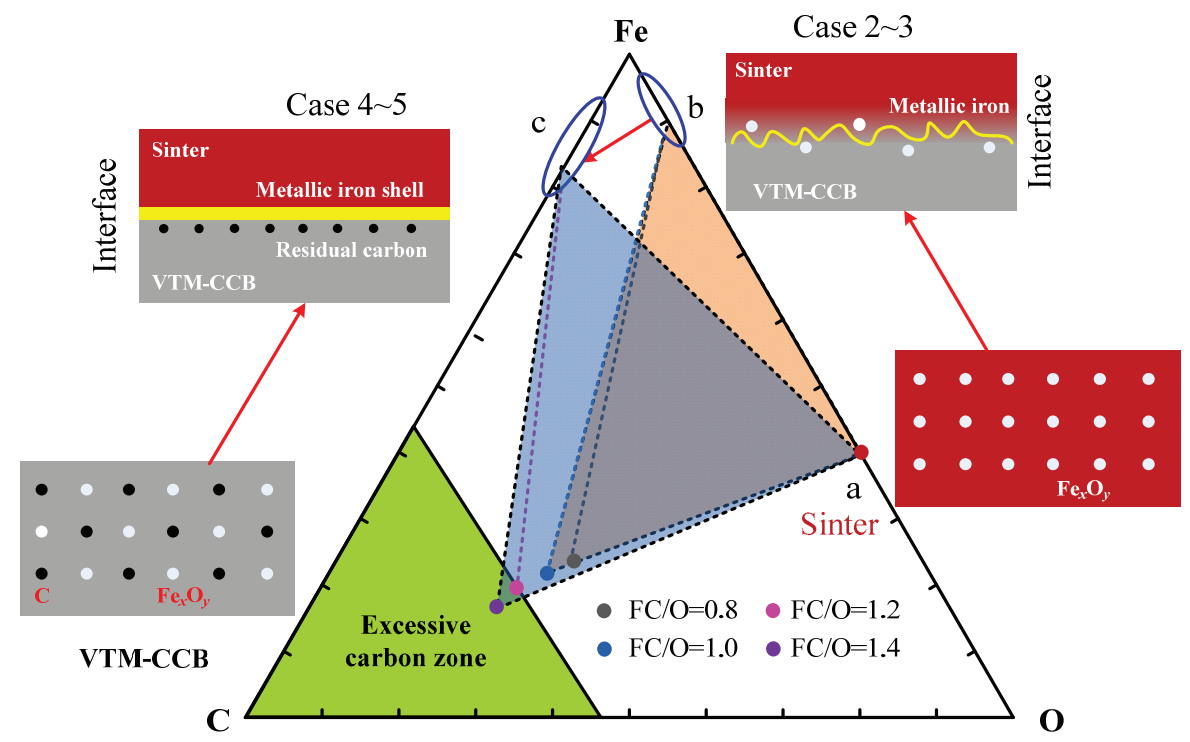

Fig. 12. $\mathrm{Fe}-\mathrm{C}-\mathrm{O}$ diagram and the interactions between $\mathrm{VTM}-\mathrm{CCB}$ and sinter in case 2-5. (Online version in color.)

the main reaction driving force at the interface along with the line $\mathrm{P}_{1} \mathrm{C}_{1}$, as shown in Fig. 11(b). In step 2, the molten slag generated at the sinter interface gradually diffused to the VTM-CCB interface, and the concentration gradient of $\mathrm{CaO}(\mathrm{NH})$ was the diffusion driving force along with the line $\mathrm{C}_{2} \mathrm{P}_{2}$, as shown in Fig. 11(b). Besides, the reduction of VTM-CCB and its effect on sinter would affect the interface slag behavior. With a $\mathrm{FC} / \mathrm{O}$ ratio of 0.8 , the reduction of VTM-CCB and sinter were limited due to the insufficient carbon, thereby increasing the wustite phases and promoting to combine with $\mathrm{CaO}, \mathrm{SiO}_{2}$ and $\mathrm{Al}_{2} \mathrm{O}_{3}$ to form low melting point slag. With increasing $\mathrm{FC} / \mathrm{O}$ ratio to 1.0 , the reduction of the sinter near the interface was strengthened further, and the molten slag decreased and metallic iron-joined crystal increased, alleviating the bonding and softening behavior, as shown in Fig. 11(c).

With increasing the $\mathrm{FC} / \mathrm{O}$ ratio of VTM-CCB higher than 1.2 , the interface transformed from slag-metal coexisting structure to density metallic iron shell. Correspondingly, the interactions between VTM-CCB and sinter mainly relied on the residual carbon and metallic iron. As shown in Fig. 12, the sinter located on $\mathrm{Fe}-\mathrm{O}$ line and the VTM-CCB located at the bottom left of $\mathrm{Fe}-\mathrm{C}-\mathrm{O}$ diagram. With a $\mathrm{FC} / \mathrm{O}$ ratio of lower than 1.0, the composite $\mathrm{Fe}-\mathrm{C}-\mathrm{O}$ system in 
VTM-CCB/sinter mixtures transformed to $\mathrm{Fe}-\mathrm{O}$ system (area $b$ ) due to the insufficient carbon content. As a result, the interface between VTM-CCB and sinter mainly consists of iron oxides, slag and metallic iron. With increasing the $\mathrm{FC} / \mathrm{O}$ ratio higher than 1.0 , the composite $\mathrm{Fe}-\mathrm{C}-\mathrm{O}$ system gradually converted to $\mathrm{Fe}-\mathrm{C}$ system (area c), and the interface mainly consists of metallic iron, slag and residual carbon. However, the molten slag was surrounded by large amounts unconsumed carbon particles, thereby weakening the bonding behavior. The transformation of the interface structure could improve the melting behavior of VTM-CCB/sinter mixtures and guarantee the reduction gas passing through, which results in the reduction was promoted and the permeability of the packed bed was improved obviously.

\subsection{Gas Permeability of VTM-CCB/sinter Mixtures}

The interactions softening-melting process have a significant effect on the gas permeability of VTM-CCB/sinter mixtures. Figure 13 presents the pressure drop and $S$ value in different cases. The $S$ value was calculated by the fol- lowing formula.

$$
S=\int_{T_{S}}^{T_{D}}\left(P_{m}-\Delta P_{S}\right) \cdot d T
$$

where $T_{\mathrm{s}}$ and $T_{\mathrm{D}}$ are the melting start temperature and dripping temperature, respectively. $P_{m}$ and $\Delta P_{S}$ are the pressure drop at certain temperatures and the pressure drop at $T_{\mathrm{s}}$, respectively. In general, a smaller $S$ value indicates a greater gas permeability of the packed bed.

As shown in Fig. 13, with increasing the temperature, the pressure drop in the 5 cases all rose at the beginning, then went down. The difference is that the maximum pressure drop decreased steeply from case 1 to case 3, and then changed slightly. Correspondingly, the $S$ value decreased firstly from case 1 to case 3 , then increased slowly. In conclusion, an appropriate $\mathrm{FC} / \mathrm{O}$ ratio of VTM-CCB could improve the gas permeability of packed bed effectively in softening-melting process.

The gas permeability of VTM-CCB/sinter mixtures during softening-melting process could be attributed to the following reasons. Firstly, as a type of carbon-bearing material,
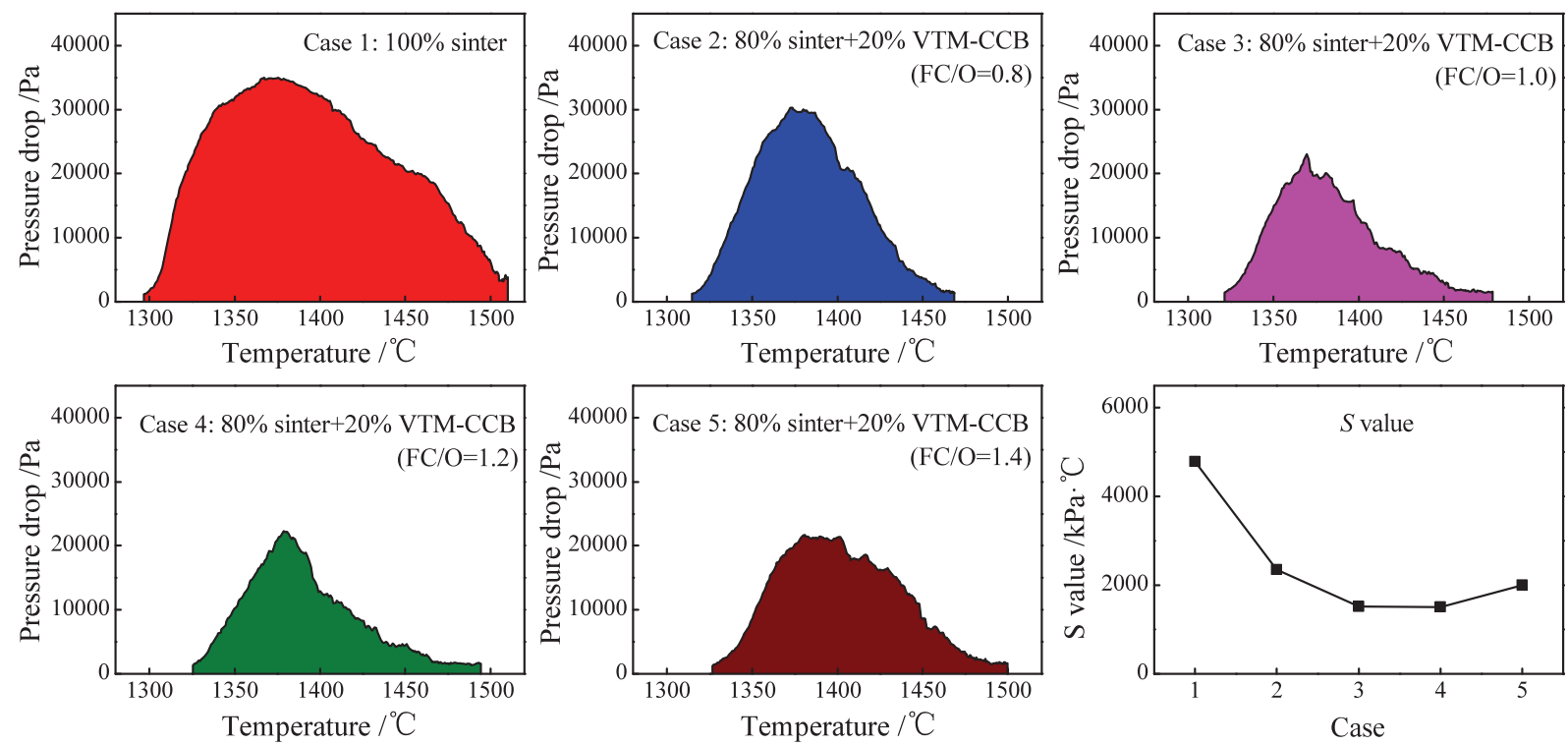

Fig. 13. Gas permeability of VTM-CCB/sinter mixtures during softening-melting process. (Online version in color.)

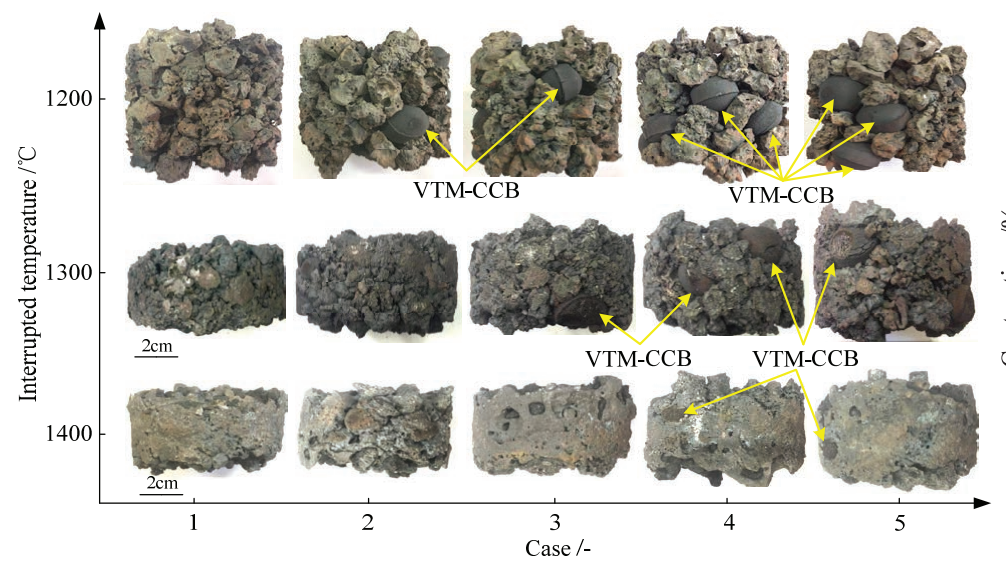

(a) morphologies of VTM-CCB/sinter mixtures

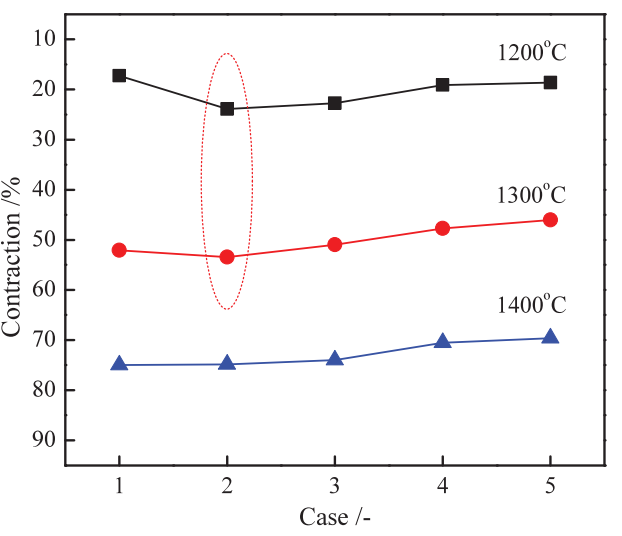

(b) contractions of VTM-CCB/sinter mixtures

Fig. 14. (a) Morphologies and (b) contractions of VTM-CCB/sinter mixtures at different interrupted temperatures. (Online version in color.) 
the VTM-CCB performs good high-temperature strength, especially for the VTM-CCB with a higher FC/O ratio. As shown in Fig. 14(a), the residual VTM-CCB would act as skeleton in the softening-melting VTM-CCB/sinter mixtures and provide large amounts gas channels and guarantee the gas passing through. It also can be proved from the contractions of the VTM-CCB/sinter mixtures during softeningmelting, as shown in Fig. $14(\mathrm{~b})$. At $1200^{\circ} \mathrm{C}$ and $1300^{\circ} \mathrm{C}$, the contractions show a relative increasing from case 1 to case 2 due to the fact that the interface slagging promoted the melting and shrinking of VTM-CCB/sinter mixtures. With further increasing the $\mathrm{FC} / \mathrm{O}$ ratio of VTM-CCB, the contractions decreased obviously, which indicates that the shrinking and collapse of the burden was alleviated. As a result, a relative porous structure of VTM-CCB/sinter mixture could improve the gas permeability. Secondly, as described above, the residual carbon in VTM-CCB would suppress the aggregation of molten iron and slag with increasing the $\mathrm{FC} / \mathrm{O}$ ratio to 1.4 . Especially, the $\mathrm{Ti}(\mathrm{C}, \mathrm{N})$ would precipitated in the molten iron, slag and carbon mixtures, thereby increasing the slag viscosity steeply and worsening the gas permeability. Therefore, in the view of improving gas permeability, the FC/O ratio of VTM-CCB should be controlled in the range from 1.0 to 1.2.

\section{Conclusions}

The interface behavior and its effect on softening-meltingdripping characteristics and gas permeability of VTM-CCB/ sinter mixtures were investigated in this paper. The following conclusions could be obtained from this study.

(1) In the softening process, when the $\mathrm{FC} / \mathrm{O}$ ratio of VTM-CCB ranges from 0.8 to 1.0 , the molten slag-metal coexisting structure formed at the interface could promote the shrinking of mixtures, thereby decreasing the $T_{4}$ and $T_{40}$. With increasing the $\mathrm{FC} / \mathrm{O}$ ratio higher than 1.0, the interface slagging and bonding phenomenon were suppressed due to the unconsumed carbon particles, which results in the softening and shrinking of mixtures were alleviated, thereby increasing the $T_{4}$ and $T_{40}$.

(2) In the melting process, with increasing $\mathrm{FC} / \mathrm{O}$ ratio of VTM-CCB, the reduction of iron oxides was promoted and the amounts of molten slag decreased obviously. The interface layer transformed from molten slag-iron coexisting structure to dense metallic iron shell, suppressing the collapse of the molten mixtures and increase the $T_{\mathrm{s}}$.

(3) In the dripping process, an appropriate $\mathrm{FC} / \mathrm{O}$ ratio of VTM-CCB could promote the interface iron carburization and accelerate the aggregation of molten iron, thereby decreasing $T_{\mathrm{D}}$ and improving the dripping performance of VTM-CCB/sinter mixtures.

(4) The VTM-CCB acting as skeleton in the molten mixtures could alleviate the shrinking and provide gas channels to improve the gas permeability. However, with increasing the $\mathrm{FC} / \mathrm{O}$ ratio to 1.4 , the $\mathrm{Ti}(\mathrm{C}, \mathrm{N})$ would precipitate at the slag-metal interface and deteriorate the fluidity of molten iron and slag, and the gas permeability deteriorated and $T_{\mathrm{D}}$ increased notably. Fully considering the interaction during softening-melting-dripping process and the gas permeability, the appropriate FC/O ratio of VTM-CCB should not be higher than 1.2.

\section{Acknowledgments}

The authors are especially thankful to National Natural Science Foundation of China (U1808212) and (51604178), Fundamental Research Funds for the Central Universities (N172503016).

\section{REFERENCES}

1) J. J. Xin, N. Wang, M. Chen and C. Chen: ISIJ Int., 60 (2020), 823.

2) J. Tang, M. S. Chu, C. Feng, F. Li, Y. T. Tang and Z. G. Liu: ISIJ Int., 57 (2017), 1156.

3) Y. H. Li, G. Chen, J. H. Peng, C. Srinivasakannan and R. S. Ruan: Powder Technol., 315 (2017), 318.

4) H. G. Du: Principle of Blast Furnace Smelting Vanadium-Titanium Magnetite, Science Press, Beijing, (1996), 1 (in Chinese).

5) K. X. Jiao, J. L. Zhang, Z. J. Liu, S. B. Kuang and Y. X. Liu: ISIJ Int., 57 (2017), 48.

6) J. S. Shiau, S. H. Liu and C. K. Ho: Mater. Trans., 53 (2012), 1449.

7) J. S. Shiau, S. H. Liu and C. K. Ho: ISIJ Int., 58 (2018), 52.

8) Y. Kashihara, Y. Morikawa, T. Sato, N. Ishiwata and M. Sato: ISIJ Int., 55 (2015), 1165.

9) S. Matsuhashi, H. Kurosawa, S. Natsui, T. Kon, S. Ueda, R. Inoue and T. Ariyama: ISIJ Int., 52 (2012), 1990.

10) Z. J. Liu, J. L. Zhang and T. J. Yang: ISIJ Int., 55 (2015), 1146.

11) K. Higuchi, J. Okazaki and S. Nomura: ISIJ Int., 60 (2020), 674.

12) J. Sterneland and P. G. Jönsson: ISIJ Int., 43 (2003), 26.

13) N. Takeuchi, Y. Iwami, T. Higuchi, K. Nushiro, N. Oyama and M. Sato: ISIJ Int., 54 (2014), 791.

14) J. Pal, S. Ghorai, M. C. Goswami, S. Prakash and T. Venugopalan: ISIJ Int., 54 (2014), 620.

15) T. Anyashiki, K. Fukada and H. Fujimoto: JFE Tech. Rep., 13 (2009),

16) A. Kasai, M. Naito, Y. Matsui and Y. Yamagata: Tetsu-to-Hagané, 89 (2003), 1212 (in Japanese).

17) A. Kasai, H. Toyota, K. Nozawa and S. Kitayama: ISIJ Int., 51 (2011), 1333.

18) Y. Matsui, M. Sawayama, A. Kasai, Y. Yamagata and F. Noma: ISIJ Int., 43 (2003), 1904.

19) H. Mizoguchi, H. Suzuki and S. Hayashi: ISIJ Int., 51 (2011), 1247.

20) R. H. Zhong, L. Y. Yi, Z. C. Huang, X. Jiang and W. Cai: ISIJ Int., 60 (2020), 649.

21) T. Y. Huang, D. Maruoka, T. Murakami and E. Kasai: ISIJ Int., 59 (2019), 1982.

22) T. Murakami, M. Ohno, K. Suzuki, K. Owaki and E. Kasai: ISIJ Int., 57 (2017), 1928

23) K. Miura, J. C. Yan, H. Ohgaki, R. Ashida and K. Ichikawa: ISIJ Int., 59 (2019), 2182.

24) W. Zhao, H. T. Wang, Z. G. Liu, M. S. Chu, Z. W. Ying and J. Tang: JOM, 69 (2017), 1737

25) W. Zhao, M. S. Chu, H. T. Wang, Z. G. Liu, J. Tang and Z. W. Ying: ISIJ Int., 58 (2018), 823.

26) W. Zhao, H. T. Wang, Z. G. Liu, M. S. Chu, J. Tang and Z. W. Ying: Powder Technol., 342 (2019), 214

27) X. L. Liu, S. L. Wu, W. Huang, K. F. Zhang and K. P. Du: ISIJ Int., 54 (2014), 2089.

28) S. L. Wu, H. L. Han, H. F. Xu, H. W. Wang and X. Q. Liu: ISIJ Int., 50 (2010), 686.

29) X. F. She, J. S. Wang, J. Z. Liu, X. X. Zhang and Q. G. Xue: ISIJ Int., 54 (2014), 2728.

30) P. Kaushik and R. J. Fruehan: Ironmaking Steelmaking, 34 (2007), 10.

31) G. J. Cheng, X. X. Xue, T. Jiang and P. N. Duan: Metall. Mater. Trans. B, 47 (2016), 1713.

32) X. L. Liu, T. Honeyands, G. Evans, P. Zulli and D. O'Dea: Ironmaking Steelmaking, 46 (2019), 953.

$33)$ S. L. Wu, B. Y. Tuo, L. H. Zhang, K. P. Du and Y. Sun: Steel Res. Int., 85 (2014), 233.

34) M. S. Chu: Raw Fuels and Auxiliary Materials in Ferrous Metallurgy, Metallurgical Industry Press, Beijing, (2010), 158 (in Chinese).

35) H. Park, J. Y. Park, G. H. Kim and I. Sohn: Steel Res. Int., 83 (2012), 150

36) N. Saito, N. Hori, K. Nakashima and K. Mori: Metall. Mater. Trans. $B, 34$ (2003), 509.

37) A. Shankar, M. Görnerup, A. K. Lahiri and S. Seetharaman: Metall. Mater. Trans. B, 38 (2007), 911.

38) Y. X. Liu, J. L. Zhang, Z. Y. Wang, K. X. Jiao, G. H. Zhang and K. C. Chou: Int. J. Miner. Metall. Mater., 24 (2017), 130.

39) G. H. Zhang, Y. L. Zhen and K. C. Chou: ISIJ Int., 55 (2015), 922.

40) Y. L. Zhen, G. H. Zhang and K. C. Chou: Metall. Mater. Trans. B, 46 (2015), 155. 